\title{
A review of two large Jurassic pterodactyloid specimens from the Solnhofen of southern Germany
}

\author{
Ross A. Elgin and David W.E. Hone
}

\begin{abstract}
Two incomplete wings recovered independently from the Jurassic limestone of southern Germany are among the largest pterodactyloid fossils known from the region. Biometric observations of the long bones suggest that they may be conspecific and together form one of two distinct skeletal configurations known within "Pterodactylus" grandis. The presence of a potentially novel species is suggested by a unique combination of postcranial characteristics not observed in any other pterosaur specimen. However, a robust method of testing its taxonomic relationship remains elusive owing to the poor representation of large and mature individuals among Jurassic pterodactyloids. While the specimens share several postcranial ratios similar to members of the Ctenochasmatoidea and Dsungaripteroidea, extrapolating bone proportions to greater sizes in named species is of limited value due to a variety of growth strategies employed throughout the Pterodactyloidea.
\end{abstract}

Ross A. Elgin. Department of Geology, Staatliches Museum für Naturkunde Karlsruhe (SMNK), Erbprinzenstrasse 13, 76133, Karlsruhe, Germany. rosselgin@gmail.com

David W.E. Hone. School of Biological and Chemical Sciences, Queen Mary University of London, Mile End Road, London, E1 4NS, UK. d.hone@qmul.ac.uk

Keywords: Pterosauria; Pterodactyloidea; Jurassic; Solnhofen

Submission: 2 November 2016. Acceptance: 12 March 2020.

\section{INTRODUCTION}

The Late Jurassic Solnhofen limestones in southern Germany represent a most productive and well-studied sequence of deposits from which hundreds of pterosaur fossils are known. While successive reviews of this fauna have indicated the presence of at least 10 pterodactyloid and non- pterodactyloid species displaying a range of ontogenetic characteristics (e.g., Wellnhofer, 1970, 1975; Bennett, 1995, 1996; Jouve, 2004; Bennett, 2013a, 2013b), some interpretations remain controversial (Jouve, 2004; Bennett, 2013a; Vidovic and Martill, 2014, 2017) and preservation is heavily skewed towards the favorable preservation of juvenile or ontogenetically immature individuals (Ben-

Elgin, Ross A. and Hone, David W.E. 2020. A review of two large Jurassic pterodactyloid specimens from the Solnhofen of southern Germany. Palaeontologia Electronica, 23(1):a13. https://doi.org/10.26879/741

palaeo-electronica.org/content/2020/2976-solnhofen-pterodactyloids 
nett, 1995, 1996). In spite of this bias, large and mature specimens are known (Wellnhofer, 1970) and although rare, indicate that these animals must have remained at least periodically within the local ecosystem. As a result, a significant size discrepancy is observed within the more diverse, although less numerous, pterodactyloids of the local area. The majority of osteologically immature specimens possess wingspans ranging between $0.17 \mathrm{~m}$ and 1 $\mathrm{m}$ (Sullivan et al., 2014), while the largest and most mature individuals are known to be in excess of 2 $\mathrm{m}$, but lack a reliable taxonomic designation (Wellnhofer, 1970). Instead, the largest individuals were collectively assigned to "Pterodactylus" grandis (Cuvier, 1824) or "Pterodactylus" grandipelvis (von Meyer, 1859), nomen dubia where specimens are united only by a common size and the absence of the cranial elements that are most widely used for identification (Unwin, 2003; Andres et al., 2014).

This report focuses on two undescribed and partial pterodactyloid specimens from the Solnhofen Limestone of Germany also displaying signs of skeletal maturity and estimated wingspans in excess of $2 \mathrm{~m}$ in length. In light of recent revisions of Solnhofen pterodactyloids, this presents an opportunity to revisit the relationships of the largest specimens and permits a comparison to named taxa within the Solnhofen locale with respect to their skeletal biometrics and postcranial anatomy. Establishing any such relationship would represent an important step towards better understanding the palaeobiology, developmental and life histories of early pterodactyloid pterosaurs.

\section{Institutional Abbreviations}

NHMUK, Natural History Museum, London, UK; BSP, Bayerische Staatssammlung für Paläontologie und Geologie, Munich, Germany; GPIT, Geologisch-Paläontologisches Institut, Tübingen, Germany; MB, Museum für Naturkunde, LeibnizInstitut für Evolutions- und Biodiversitätsforschung, Berlin, Germany; NMB, Naturhistorisches Museum Basel, Basel, Switzerland; PTH, PhilosophischTheologische Hochschule, Eichstätt, Germany; RGM, Nationaal Natuurhistorisch Museum, Leiden, The Netherlands; SMNK, Staatliches Museum für Naturkunde Karlsruhe, Germany.

\section{DESCRIPTIVE PALAEONTOLOGY}

\section{Description of MB.R.5591.1}

Collection number. MB.R.5591.1
Repository. Museum für Naturkunde, LeibnizInstitut für Evolutions- und Biodiversitätsforschung, Berlin, Germany.

Locality information. Unknown locality, Eichstätt area, Germany.

Horizon. Solnhofen Limestone (Upper Jurassic)

Notes. A label attached to the matrix indicates that the specimen was collected near the Eichstätt area of southern Germany, and it is incorrectly labeled as "Rhamphorhynchus."

Description. The specimen is comprised of a partial forelimb consisting of all the elements minus the humerus and most of digits I-III (Figure 1.1-2). The fossil is embedded in a split plate (MB.R.5591.1) of pale yellow limestone containing numerous grey dendrites. Most preserved elements are crushed and missing large sections of the cortex, which has exposed the internal cavities of the bones. Owing to significant damage to each of the key surfaces and articulations it is not certain if this is a left or right forelimb. There are no traces of trabeculae inside the long bone shafts, which were clearly hollow. There is some infill of matrix into the cavities of the long bones and in some places a buildup of calcite.

The humerus is not preserved. The ulna is preserved as a long and straight element that is missing much of the cortex. The presence of a radius, which lies below the ulna and cannot be observed fully, is inferred from the size and shape of some pieces of bone proximally.

A series of small cavities in the matrix lie next to the joint between the ulna and metacarpal IV and presumably represent the location of unpreserved sesamoids (Figure 2.1). These are in association with the pteroid, which is long, slender, and nearly straight. A large and sub-rectangular element lies alongside the proximal part of the metacarpal. This is inferred to represent the displaced proximal and distal syncarpals lying together but slightly removed from their natural position.

Metacarpal IV is preserved almost entirely as a bone-lined cavity in the matrix. Proximally, the shape is clearly visible, but distally this lies deeper in the matrix such that the distal end is barely visible and only a thin splint of bone can be seen. Towards the distal part of metacarpal IV a thin groove is visible in the matrix and diverges from the main element. This is inferred to be one of metacarpals I-III, but the exact identity cannot be determined. A second cavity in the matrix lying anterior to these is interpreted as a second preaxial metacarpal that has dissociated and moved away 

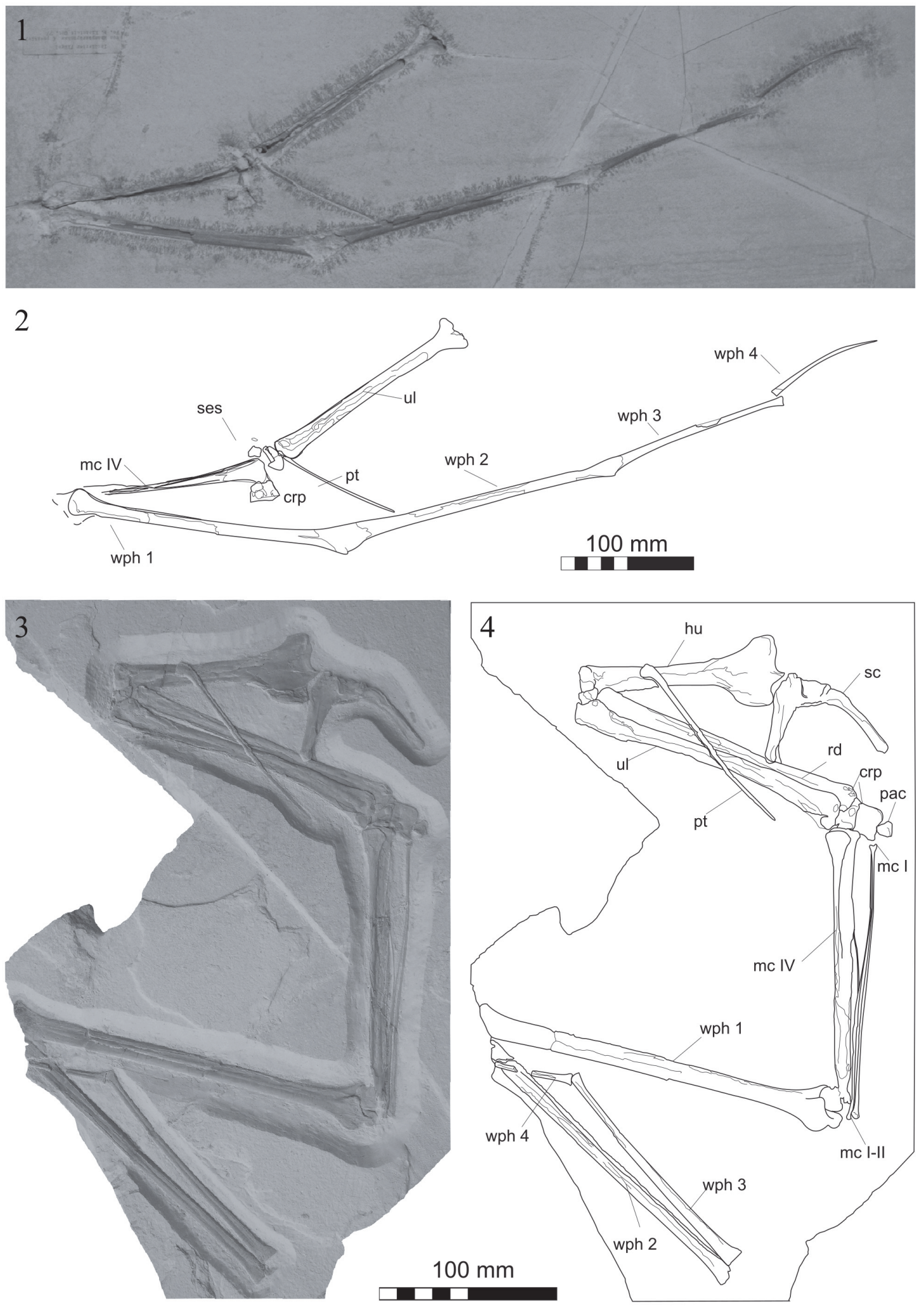

FIGURE 1. Overview of the described specimens. MB.R.5591.1: (1) photograph of main slab and (2) composite line tracing of slab and counter slab. SMNK PAL 6990: (3) photograph and (4) corresponding line tracing. sc, scapulocoracoid; hu, humerus; $r d$, radius; $u l$, ulna; $c r p$, carpals (syncarpals); $p t$, pteroid; pac, preaxial carpal; ses, sesamoid; $m c$, metacarpal; wph, wing-finger phalanx (digit 4). 

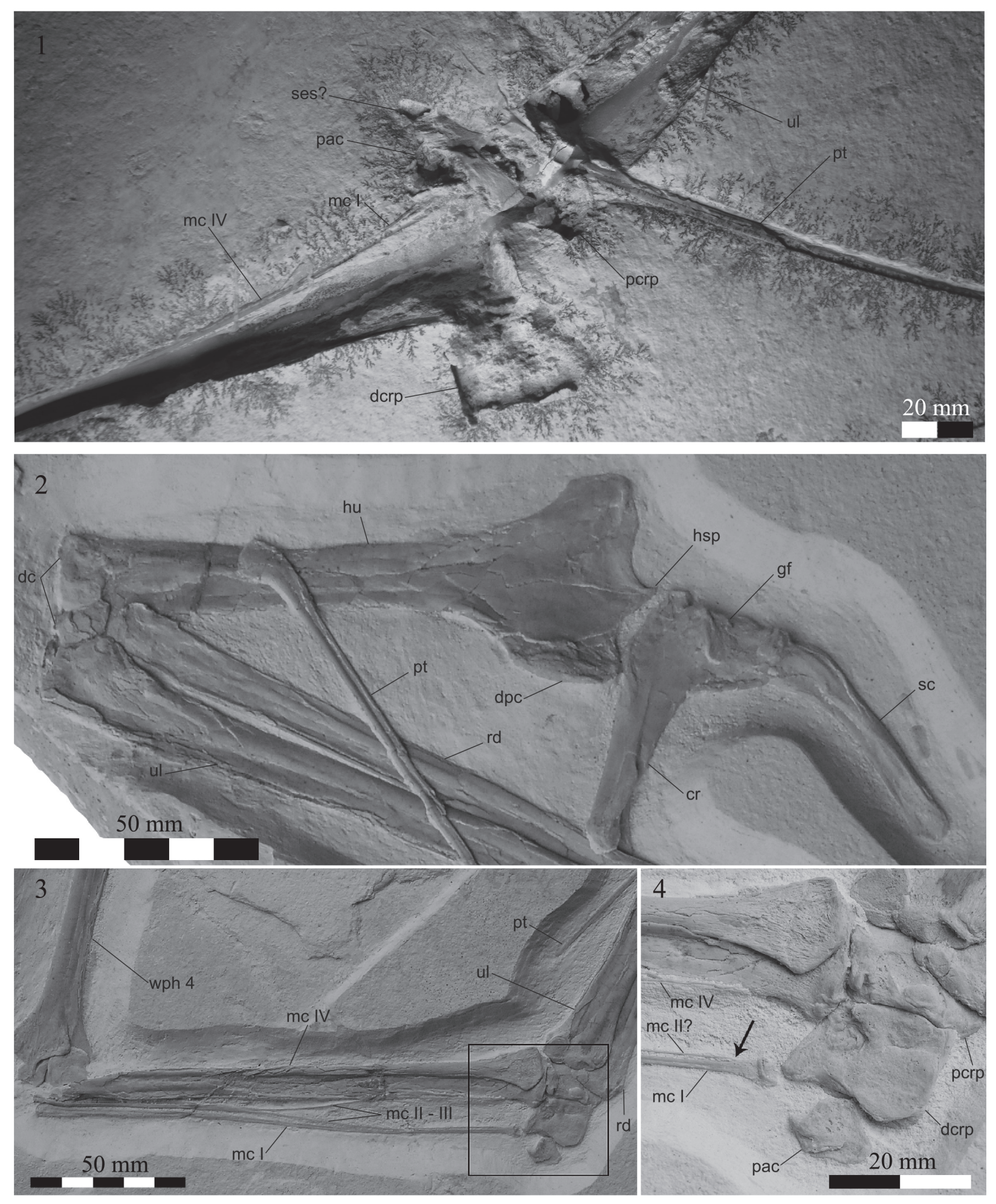

FIGURE 2. Closer details of the described specimens. (1) Syncarpals of MB.R.5591.1. (2) Humeral head and scapulocoracoid articulation of SMNK PAL 6990; (3) Metacarpals of SMNK PAL 6990 and (4) close up of the proximal terminations within the boxed area. Syncarpals of SMNK PAL 6990 with the small arrow indicating the most proximal end of the $2^{\text {nd }}$ metacarpal. $s c$, scapula; $c r$, coracoid; $g f$, glenoid fossa; $h s p$, hook-shaped protuberance; $d p c$, deltopectoral crest; $h u$, humerus; $d c$, distal condyles; $r d$, radius; ul, ulna; $p t$, pteroid; $p c r p$, proximal syncarpus; $d c r p$, distal syncarpus; pac, preaxial carpal; ses, sesamoid; $m c$, metacarpal; wph, wing finger phalanx (digit 4). 
from metacarpal IV. There are no traces of digits IIII in the matrix.

The proximal end of phalanx IV-1 overlaps the distal end of metacarpal IV, but poor preservation of both means that only their outlines are visible. Immediately distal to this overlap is a somewhat Lshaped depression in the matrix lined with cortical bone. The identity of this element is not clear but, based on the position and size, it is considered most likely to pertain to the unfused extensor tendon process of phalanx IV-1 that has become displaced.

The wing phalanges are in near articulation, with phalanges 1-3 being aligned and phalanx 4 being slightly displaced. The shafts of phalanges $1-$ 4 of the wing finger are relatively well preserved, though the proximal and distal areas where they meet are damaged and unclear. The fourth phalanx shows a marked curvature along its length, though the others are all straight.

The counter plate contains few bones or impressions, however, the surface of the matrix represents a high-fidelity copy of the cortex external surface. Some impressions of the midline of elements on the counter plate are raised above the surface of the matrix (e.g., wing phalanx 2) suggesting that the bones were crushed prior to, or during, fossilisation.

\section{Description of SMNK PAL 6990}

Collection Number. SMNK PAL 6990

Repository. Staatliches Museum für Naturkunde Karlsruhe, Karlsruhe, Germany.

Locality information. Unknown locality, Solnhofen region, Germany.

Horizon. Solnhofen Limestone (Upper Jurassic)

Notes. Specimen was purchased from a private dealer on behalf of the Staatliches Museum für Naturkunde Karlsruhe and is noted as having originated from the platy limestone around Solnhofen, southern Germany.

Description. The specimen is comprised of the left scapulocoracoid along with the majority of the left forelimb and is preserved on a single slab of white/ grey limestone with no counter plate (Figure 1.3-4).

The scapula and coracoid are preserved in posterior view and have fused into a single element with no visible suture (Figure 2.2). Both bones are of equal length, $62 \mathrm{~mm}$, measured from their medial termini to the midpoint of the glenoid. The coracoid is broad but tapers medially, and the medial termination of the coracoid is forked for the articulation with the sternum. The shaft of the scapula is dorsoventrally compressed to a greater degree than that of the coracoid. Relative to the shafts of the two rami the glenoid fossa is greatly expanded, U-shaped in dorsoventral section, and extends across much the posterior surface of the scapulocoracoid. A pronounced biceps tubercle is present ventral to the glenoid fossa.

The humerus is a slender element that is exposed in ventral view. An exaggerated hookshaped protuberance is present on the proximomedial margin of the bone where the caput converges with the deltopectoral crest. The deltopectoral crest is trapezoid shaped, with concave medial and lateral margins that merge with the caput and the shaft, respectively, while the posterior process is smaller but similarly shaped (Figure 2.2). The shaft is long, straight, and expands gently towards its distal margin, the distal articular surface of which is formed by two prominent condyles, the trochlea and capitulum. No foramina or pneumatic features are visible on the humerus.

The radius and ulna are long and straight, sub-equal in length, and lie adjacent to the carpus. The radius has been displaced a short distance distally from its natural position by the flexing of the antebrachial elements. The distal articular face of the ulna is comprised of a smooth, slightly concave surface, bordered by a low ridge of bone on the dorsal half of the articulation. A small circular depression is present on the ventral half of the articular surface.

The carpals are fused into proximal and distal syncarpals and have been slightly displaced from their natural positions. The medial face of the proximal element is partially overlain by the radius and ulna, but is sub-rectangular in shape with a bulbous tubercle on the anteroventral edge of the articulation. The distal syncarpal is exposed in its medial aspect with the dorsal margin of the bone being overlain by the proximal syncarpal. The distal element is crushed but also appears sub-rectangular in shape with a short, anterior directed protuberance (i.e., anterior distal carpal) onto which the preaxial carpal would have been positioned during life. The preaxial carpal lacks an accompanying sesamoid. The pteroid has been displaced medially and overlies the radius, ulna, and humerus. It is a narrow and elongate bone, tapering slowly along its length, and terminating in a rounded distal end. The caput has expanded relative to the shaft and has a rounded proximal margin. The shaft meanwhile is offset against the caput at an angle of $41^{\circ}$ and is distally curved in such a way that, in combination with the turned proximal head, the overall element is weakly sigmoidal in shape. 
TABLE 1. Selected long bone measurements of large Jurassic pterosaurs. Hu, humerus; UI, ulna; Mc, metacarpal; Wph, wing finger phalanx; WF, wing finger (wph 1-4); FL, forelimb (i.e., half span); FL-WF representing the combined length of the humerus, ulna, and metacarpal. All measurements are in $\mathrm{mm}$. Incomplete bones $\left(^{*}\right)$ attributed to the 'big wings' are reconstructed based on more complete specimens (Appendix 1).

\begin{tabular}{|c|c|c|c|c|c|c|c|c|c|c|c|}
\hline & Specimen & $\mathrm{Hu}$ & UI & Mc 4 & Wph 1 & Wph 2 & Wph 3 & Wph 4 & FL-WF & WF & FL \\
\hline \multicolumn{12}{|c|}{ 'big wings' (Configuration \#1) } \\
\hline 1 & SMNK PAL 6990 & 129 & 174 & 165 & 224 & 216 & 142 & 72 & 468 & 654 & 1120 \\
\hline 2 & MB.R.5591.1 & $117^{*}$ & 158 & 141 & 215 & 191 & 141 & 93 & $420^{*}$ & 640 & 1060 \\
\hline 3 & Lost (see Wellnhofer, 1970) & 130 & 185 & 162 & - & - & - & - & 477 & - & - \\
\hline \multicolumn{12}{|c|}{ 'big wings' (Configuration \#2) } \\
\hline 4 & PTH 1963.1A & 116 & 133 & 140 & 182 & 171 & - & - & 389 & - & - \\
\hline \multicolumn{12}{|c|}{ 'big wings' (indet.) } \\
\hline 5 & Lost (see Wellnhofer, 1970) & - & 174 & - & - & 194 & - & - & - & - & - \\
\hline 6 & $\begin{array}{l}\text { Eichstätt sp. (see Wellnhofer, } \\
\text { 1970) }\end{array}$ & - & - & - & 200 & 195 & 185 & - & - & - & - \\
\hline \multicolumn{12}{|c|}{ Named Taxa } \\
\hline 7 & $\begin{array}{l}\text { Germanodactylus cristatus } \\
\text { (BSP AS I745) }\end{array}$ & 56 & 75 & 66 & 84 & 78 & 66 & 55 & 197 & 282 & 479 \\
\hline 8 & $\begin{array}{l}\text { Cycnorhamphus suevicus } \\
\text { (GPIT 80) }\end{array}$ & 64 & 88 & 111 & 142 & 117 & 85 & 71 & 263 & 415 & 678 \\
\hline 9 & $\begin{array}{l}\text { Ardeadactylus longicollum } \\
\text { (Stuttgart sp) }\end{array}$ & 95 & 115 & 160 & 188 & 134 & - & - & 370 & - & - \\
\hline 10 & $\begin{array}{l}\text { Pterodactylus antiquus } \\
\text { (RGM St } 18 \text { 184) }\end{array}$ & 44 & 60 & 44 & 58 & 58 & 51 & 39 & 148 & 205 & 353 \\
\hline 11 & $\begin{array}{l}\text { Aurorazhdarcho micronyx } \\
\text { (NMB Sh 110) }\end{array}$ & 63 & 84 & 99 & 123 & 85 & 59 & 52 & 246 & 319 & 565 \\
\hline 12 & $\begin{array}{l}\text { Ctenochasma elegans } \\
\text { (BSP 1935 I 24) }\end{array}$ & 39 & 53 & 35 & 66 & 57 & - & - & 127 & - & - \\
\hline 13 & $\begin{array}{l}\text { Aerodactylus scolopaciceps } \\
\text { (see Frey and Martill 1998) }\end{array}$ & 64 & 89 & 61 & - & - & - & - & 214 & - & - \\
\hline
\end{tabular}

The preaxial metacarpals are sub-equal in length to metacarpal IV. The shaft of the first metacarpal retains a more or less constant diameter along its length with a strongly concave articular surface positioned on its proximal margin (Figure 2.3-4). From this, a natural contact with the distal syncarpal during life is inferred. In contrast, the second and third metacarpals are bulbous only at their distal margins and begin to taper strongly in the direction of the carpus about half way along their length. Whether the proximal termini of these bones ever made contact with the distal carpus is uncertain owing to the poor preservation of metacarpal II, while metacarpal III is obscured from view by the first element $(\mathrm{mc} \mathrm{l}) 56 \mathrm{~mm}$ distal to the carpus. The fourth metacarpal is elongate (95\% of the length of the ulna) but has been badly damaged due to crushing. A short flange is present along the ventral margin of the anterior face of the shaft, originating from the proximal margin of the bone. The distal ventral condyle is broken where it meets the shaft.

Phalanx 1 of digit IV has fused with the extensor tendon process and no suture is visible. The proximal articular surface is formed by two cotyles to accommodate the distal condyles of the wing metacarpal, the larger of the two being located dorsally. The ventral cotyle overlaps the ventral surface of the condyle on the fourth metacarpal, indicating that the two elements remain in articulation. The shaft narrows distal to the proximal articulation, expanding again only at the distal portion of the bone. A portion of the articular end of phalanx 1 is missing off the edge of the matrix block but enough is present to determine an approximate length for the element (Table 1). The remaining three phalanges of the wing finger are slender elements that preserve only a very slight curvature along their lengths. The proximal and distal portions are expanded for articulation with their neighbouring element. Although only the third phalanx is 
complete it is clear that the wing phalanges decrease in length sequentially.

\section{DISCUSSION}

While larger specimens have been unearthed from contemporary locales (Meyer and Hunt, 1999), the two described here are counted among the largest pterodactyloids known from the Jurassic limestone of southern Germany (Table 1). The more complete of the two, SMNK PAL 6990, has an estimated forelimb length of $1.18 \mathrm{~m}$, which translates into a total wingspan of $2.24 \mathrm{~m}$ if the carpus and scapulocoracoid are omitted to account for the natural flexion of the limb (Bennett, 2001a). Although the humerus of MB.R.5991.1 is missing, the similarities in ratios of the wing finger phalanges between MB.R.5991.1 and SMNK PAL 6990 suggest that the length of the humerus can be reconstructed based on the second individual. The humerus of MB.R.5591.1 is therefore estimated to have been $117 \mathrm{~mm}$ (i.e., humeral length $=0.74 \mathrm{x}$ ulna length) to give the limb length of $1.11 \mathrm{~m}$ and $\mathrm{a}$ reconstructed wingspan of $2.12 \mathrm{~m}$.

\section{Ontogeny}

The sequence of fusion within the cranial and postcranial skeleton has long been used to assess relative ontogenetic age in pterosaurs. Both described specimens exhibit the characteristic smooth bone textures and fused carpal characteristics commonly associated with osteological maturity (Bennett, 2001b), and the scapula and coracoid of SMNK PAL 6990 have fused completely to form a single element. Despite the similarity in overall size, the extensor tendon process has fused to the first wing finger phalanx in SMNK PAL 6990 (OS5 after Kellner, 2015) but not MB.R.5591.1 (OS3+ after Kellner, 2015). As this is widely regarded as one of the final sutures to close and a definitive indicator for late adulthood (Bennett, 1995, 1996; Kellner and Tomida, 2000; Bennett, 2001b; Kellner, 2015), SMNK PAL 6990 is considered to be the more osteologically mature of the two individuals.

\section{Comparative Palaeontology}

The poor preservation of elements in MB.R.5591.1 prohibits a useful comparison with other specimens, however, several anatomical features of SMNK PAL 6990 warrant a more detailed review. The scapula and coracoid elements of the scapulocoracoid are sub-equal in length as is typical for all members of the Lophocratia (Unwin, 2003). A distinction is made however between SMNK PAL 6990 and individuals of the Azhdar- choidea, as in the former, the glenoid fossa does not extend far onto the caudal face of the scapulocoracoid, and the dorsal and ventral ridges of the fossa are convergent rather than parallel with one another.

On the humerus, the margin between the collum and the proximal margin of the deltopectoral crest on SMNK PAL 6990 is marked by a hookshaped protuberance and is distinct from any specimens of the Ctenochasmatoidea and Dsungaripteroidea, whose margins meet instead at an angle of approximately $90^{\circ}$. Although a similar, but less exaggerated feature is observed on an isolated humerus of an indeterminate ?tapejarid (SMNK PAL 3856), it is not known for other azhdarchoids and does not appear to be a feature common to or indicative of the group (Lawson, 1975; Eck et al., 2011). The deltopectoral crest of SMNK PAL 6990 is unusual in that while it is elongate and rectangular, as fitting the Lophocratia (Unwin, 2003), it is more elongate parallel to the humeral shaft rather than in an anterior direction, whereas for individuals of the Lophocratia the two are typically of sub-equal length.

The preaxial metacarpals of SMNK PAL 6990, where the second and third elements are greatly diminished relative to the first, and their contact with the distal syncarpus is uncertain, further represent a state largely unknown in most Jurassic pterodactyloids (Figure 2.2). Such a state is observed within the Tapejaridae and Thalassodromidae (Kellner, 2003; Unwin, 2003; Eck et al., 2011) where only the first metacarpal contacts the distal carpus and, to a much lesser degree, in Aurorazhdarcho micronyx (NMB Sh 110; Frey et al., 2011), extending its presence to both the Azhdarchoidea and Ctenochasmatoidea (Unwin, 2003).

\section{Morphometrics}

A comparison of bone lengths between SMNK PAL 6990, MB.R.5991.1 and specimens referred to "Pterodactylus" grandis implies the presence of two broad skeletal configurations among adult individuals. To avoid confusion, the term 'big wing' is generally adopted here to collectively cover all large, mature specimens so described or assigned to a nomen dubium. The first of these 'big wing' configurations is comprised of specimens where the ulna is longer than the humerus and fourth metacarpal, while the humerus is the shortest of the three elements (Table 1; Wagner, 1852; Wellnhofer, 1970). The second configuration is represented by a single specimen (Table 1) where the ulna and fourth 
metacarpal are sub-equal in length, but the latter is marginally longer. Using such broad configurations to group specimens rather than absolute bone ratios has an advantage when dealing with such small and incomplete datasets where variations in bone ratios are unknown, and extrapolating developmental series to larger sizes is problematic owing to a variety of growth strategies adopted within the Pterosauria (Chinsamy et al., 2008). By contrast the longest and shortest elements within the preaxial long bones appear to be quickly established at small sizes, with the notable exception of Aurorazhdarcho micronyx, and do not appear to alter afterwards (Bennett, 2001b; Codorniú and Chiappe, 2004; Appendix 1).

Using these concepts, three species from the Solnhofen locales are shown to be distinct from the first 'big wing' configuration, these being: Aurorazhdarcho micronyx, Cycnorhamphus suevicus and Ardeadactylus longicollum, for which the fourth metacarpal is significantly longer than either the ulna or humerus. The idea that allometric development of these bones later in ontogeny might produce a similar configuration is rejected due to the observed changes in bone proportions during the earlier stages of their life history (Appendix 1), and the size and maturity of the 'big wing' specimens. Although each of the three species share a common configuration with the second of the 'big wing' configuration where fourth metacarpal is longer than the ulna that is longer than the humerus, the sub-equal relationship of the metacarpal and ulna is so unusual in large adult specimens that any relationship is tentative at best. Sub-equal ulna and metacarpal are almost always associated with juvenile individuals and they are shown to change during later ontogeny (e.g., Au. micronyx).

Further comparisons of 'big wing' bone configurations with Ctenochasma elegans, Pterodactylus antiquus, Aerodactylus scolopaciceps, Diopecephalus kochi, and Germanodactylus cristatus, the remaining members of the Ctenochasmatoidea and Dsungaripteroidea for which a postcranial skeleton is known (Vidovic and Martill, 2014), remain uninformative. All species possess near identical forearm proportions in which the ulna is the largest of the pre-phalangeal long bones. While relatively large skulls belonging to $P$. antiquus (Bennett, 2013a) or Gnathosaurus subulatus (von Meyer, 1834; Mayr, 1964) confirm that species could grow to larger sizes than indicated by the presently known suite of juvenile specimens, the lack of any associated postcranial elements prevents useful discussion.

\section{Wider relationships of 'big wing' specimens}

In spite of the addition of new fossils, the taxonomic relationships of the 'big wing' specimens are difficult to determine owing to their unusual or unique proportions and anatomical features. Although the skeletal material is limited to forelimbs, the 'big wings' lack a number of characters that are diagnostic of established taxonomic groups, suggesting that they are unlikely to be members of them. For example, the humerus to metacarpal IV ratios are larger than that of the Nyctosauridae (Kellner, 2003, character 54); in addition to the form of the scapulocoracoid the radii and ulnae are sub-equal in diameter, suggesting they do not belong to the Ornithocheiridae or Istiodactylidae (Kellner, 2003, character 62); and the ratio of the first and second phalanges would rule out the Azhdarchoidea. The rectangular shape of the deltopectoral crest (Unwin, 2003), shape of the scapulocoracoid and limited intrusion of the glenoid onto its caudal face are indicative for some members of the Lophocratia, while a proportionally long pteroid (Kellner, 2003, character 63) was considered to be diagnostic of the Dsungaripteroidae. Given that the previous characters would suggest that the SMNK PAL 6990 is not a member of the azhdarchoids, this would point to a dsungaripterid identity (sensu Unwin, 2003) if not for the reduction of the proximal parts of metacarpals I-III (seen in at least some specimens) that are considered diagnostic of the Pteranodontidae and Azhdarchidae (Unwin, 2003, character 37). While this may contradict the above diagnosis, reduction of the metacarpalia in two specimens of the Ctenochasmatoidea (Wellnhofer, 1970; Frey et al., 2011) suggests that this character may be more widespread than previously realized, indicating that placement within either the Ctenochasmatoidea or Dsungaripteridae is most appropriate for at least SMNK PAL 6990. While it is useful that three pterodactyloid species local to the Solnhofen can be actively discounted from consideration, the overall similarity in body plan and uncertainties surrounding developmental patterns and isolated cranial remains (e.g., Gnathosaurus subulatus) mean that further taxonomic discussion is limited. Furthermore, the unusual combination of postcranial characteristics observed within SMNK PAL 6990 leaves the possible identity of the specimen and 'big wings' groups open to question. It may also be possible to argue that the individuals described herein represent a novel taxon, since they bear characteristics not normally found in combination in a variety of major pterodactyloid clades. 


\section{CONCLUSIONS}

The two new large pterodactyloid specimens from the Solnhofen Limestone of southern Germany share a common size and skeletal proportions with one individual of "Pterodactylus" grandis, suggesting that this designation currently comprises at least two morphologically distinct species. In spite of a unique combination of postcranial features within SMNK PAL 6990, including the substantial reduction of the second and third metacarpalia, and unusual humeral morphology, a placement within either the Ctenochasmatoidea or Dsungaripteridae appears most likely. While both groups are well documented from the Solnhofen Limestone and a biometric comparison rules out any possible relationships with Aurorazhdarcho micronyx, Cycnorhamphus suevicus, and Ardeadactylus longicollum, the remaining taxa are so similar in postcranial proportions that further differentiation is impossible.

\section{ACKNOWLEDGEMENTS}

The authors extend their thanks to E. Frey of the SMNK and D. Schwarz-Wings at the NMB for allowing them to work on featured specimens, and to $\mathrm{S}$. Vidovic for several helpful discussions the taxonomy of Jurassic pterosaurs. Further acknowledgements go to several anonymous reviewers for their helpful comments and guidance in finalizing this manuscript.

\section{REFERENCES}

Andres, B., Clark, B., and Xu, X. 2014. The earliest pterodactyloid and the origin of the group. Current Biology, 24:1011-1016. https://doi.org/10.1016/j.cub.2014.03.030

Bennett, S.C. 1995. A statistical study of Rhamphorhynchus from the Solnhofen Limestone of Germany: Year-classes of a single large species. Journal of Paleontology, 69:569-580. https://doi.org/10.1017/s0022336000034946

Bennett, S.C. 1996. Year-classes of pterosaurs from the Solnhofen Limestone of Germany: Taxonomic and systematic implications. Journal of Vertebrate Palaeontology, 16:432-444. https://doi.org/10.1080/02724634.1996.10011332

Bennett, S.C. 2001a. The osteology and functional morphology of the Late Cretaceous pterosaur Pteranodon. Part II. Size and functional morphology. Palaeontographica, Abteilung A, 260:113-153.

Bennett, S.C. 2001b. The osteology and functional morphology of the Late Cretaceous pterosaur Pteranodon. Part I. General description of osteology. Palaeontographica, Abteilung A, 260:1112.

Bennett, S.C. 2013a. New information on body size and cranial display structures of Pterodactylus antiquus, with a revision of the genus. Paläontologische Zeitschrift, 87:269289. https://doi.org/10.1007/s12542-012-0159-8

Bennett, S.C. 2013b. The morphology and taxonomy of the pterosaur Cycnorhamphus. Neues Jahrbuch für Geologie und Paläontologie, Abhandlungen, 267:23-41. https://doi.org/10.1127/ 0077-7749/2012/0295

Chinsamy, A., Codorniú, L., and Chiappe, L. 2008. Developmental growth patterns of the filterfeeding pterosaur, Pterodaustro guiñazui. Biology Letters, 4:282-285. https://doi.org/10.1098/ rsbl.2008.0004

Codorniú, L. and Chiappe, L.M. 2004. Early juvenile pterosaurs (Pterodactyloidea: Pterodaustro guinazui) from the Lower Cretaceous of central Argentina). Canadian Journal of Earth Sciences, 41:9-18. https://doi.org/10.1139/e03-080

Cuvier, G. 1824. $3^{\text {rd }}$ Ed., Recherches sur les Ossemens Fossiles des Quadrupèdes. Volume 5, Part 2. G. Dufour and E. d'Ocagne, Paris.

Eck, K., Elgin, R.A., and Frey, E. 2011. On the osteology of Tapejara wellnhoferi Kellner 1989 and the first occurrence of a multiple specimen assemblage from the Santana Formation, Araripe Basin, NE-Brazil. Swiss Journal of Palaeontology, 130:277-296. https://doi.org/ 10.1007/s13358-011-0024-5

Frey, E. and Martill, D.M. 1998. Soft tissue preservation in a specimen of Pterodactylus kochi (Wagner) from the Upper Jurassic of Germany. Neues Jahrbuch für Geologie und Paläontologie, Abhandlungen, 210:421-441. https://doi.org/10.1127/njgpa/210/1998/421 
Frey, E., Meyer, C.A, and Tischlinger, H. 2011. The oldest azhdarchoid pterosaur from the Late Jurassic Solnhofen Limestone (Early Tithonian) of Southern Germany. Swiss Journal of Geosciences, 104:35-55.

Jouve, S. 2004. Description of the skull of a Ctenochasma (Pterosauria) from the latest Jurassic of eastern France, with a taxonomic revision of European Tithonian Pterodactyloidea. Journal of Vertebrate Paleontology, 24:542-554. https://doi.org/10.1671/02724634(2004)024[0542:dotsoa]2.0.co;2

Kellner, A.W.A. 2003. Pterosaur phylogeny and comments on the evolutionary history of the group, p. 105-137. In Buffetaut, E. and Mazin, J.-M. (eds.), Evolution and Palaeobiology of Pterosaurs. Geological Society, London, Special Publications 217. https://doi.org/10.1144/ gsl.sp.2003.217.01.10

Kellner, A.W.A. 2015. Comments on Triassic pterosaurs with discussion about ontogeny and description of new taxa. Anais da Academia Brasileira de Ciências, 87:669-689. https:// doi.org/10.1590/0001-3765201520150307

Kellner, A.W.A. and Tomida, Y. 2000. Description of a new species of Anhangueridae (Pterodactyloidea) with comments on the pterosaur fauna from the Santana Formation (Aptian-Albian), northeastern Brazil. National Science Museum Monographs Tokyo, 17:1138.

Lawson, D.A. 1975. Pterosaur from the latest Cretaceous of west Texas: discovery of the largest flying creature. Science, 187:947-948. https://doi.org/10.1126/science.187.4180.947

Mayr, F.X. 1964. Die Naturwissenschaftlichen Sammlungen der Philosophisch-theologischen Hochschule Eichstätt, p. 302-334. In Festschrift 400 Jahre Collection Willibald. Eichstätt, Brönner and Daenter.

Meyer, C.A. and Hunt, A.P. 1999. The first pterosaur from the Late Jurassic of Switzerland: Evidence for the largest Jurassic flying animal. Oryctos, 2:111-116.

Sullivan, C., Wang, Y., Hone, D.W.E., Wang, Y.Q., Xu, X., and Zhang, F. 2014. The vertebrates of the Jurassic Daohugou Biota of northeastern China. Journal of Vertebrate Paleontology, 34:243-280. https://doi.org/10.1080/02724634.2013.787316

Unwin, D.M. 2003. On the phylogeny and evolutionary history of pterosaurs, p. 139-190. In Buffetaut, E. and Mazin, J.-M. (eds.), Evolution and Palaeobiology of Pterosaurs. Geological Society, London, Special Publications 217. https://doi.org/10.1144/gsl.sp.2003.217.01.11

Vidovic, S.U. and Martill, D.M. 2014. Pterodactylus scolopaciceps Meyer, 1860 (Pterosauria, Pterodactyloidea) from the Upper Jurassic of Bavaria, Germany: The problem of cryptic pterosaur taxa in early ontogeny. PLoS ONE, 9:e110646. https://doi.org/10.1371/ journal.pone.0110646

Vidovic, S.U. and Martill, D.M. 2017. The taxonomy and phylogeny of Diopecephalus kochi (Wagner, 1837) and 'Germanodactylus rhamphastinus' (Wagner, 1851), p.1-23. In Hone, D.W.E., Witton, M.P., and Martill, D.M. (eds.), New Perspectives on Pterosaur Palaeobiology. Geological Society, London, Special Publications, 455. https://doi.org/10.1144/sp455.12

von Meyer, H. 1834. Gnathosaurus subulatus, ein Saurus aus dem lithographischen Schiefer von Solnhofen. Museum Senckenbergianum, 1:5-7.

von Meyer, H. 1859. Zur Fauna der Vorwelt. Vierte Abt: Reptilien aus dem lithographischen Schiefer des Jura in Deutschland und Frankreich:1-84.

Wagner, A. 1852. Neu-aufgefundene Saurier-Überreste aus den lithographischen Schiefern und dem oberen Jurakalke. Abhandlungen der Bayerischen Akademie der Wissenschaften Mathematisch-Physikalische Klasse, 6:661-709.

Wellnhofer, P. 1970. Die Pterodactyloidea (Pterosauria) der Oberjura-Plattenkalke Süddeutschlands. Verlag der Bayerischen Akademie der Wissenschaften, 141:1-161.

Wellnhofer, P. 1975. Die Rhamphorhynchoidea (Pterosauria) der Oberjura-Plattenkalke Süddeutschlands. Teil III: Palökologie und Stammesgeschichte. Palaeontographica Abteilung A, 148:1-186. 


\section{APPENDIX 1}

Supplementary measurements for Jurassic pterodactyloids comparable to the described specimens and suitable for comparison. Workbook 1 lists the specimen number, taxonomy and absolute measurements of all fossils considered. Workbook 2 provides the same information but with long bone measurements converted to ratios. Workbook 3 notes the largest and smallest wing bones for each specimen and taxonomic grouping. Workbook 4 covers all references noted within the Appendix. This is presented in a multipage spreadsheet at https://palaeo-electronica.org/content/2020/2976-solnhofen-pterodactyloids. 